\title{
Phase Diagram, Caesium-133 NMR Spectra and Electrical Conductivity of the Binary System Caesium and Zinc Butyrates
}

\author{
T. A. Mirnaya, V. V. Trachevski, V. S. Dradrakh, and D. V. Bylina \\ The V. Vernadski Institute of General and Inorganic Chemistry of the Ukrainian Academy \\ of Sciences, 32-34 Prospect Palladina, 03680 Kiev-142, Ukraine
}

Reprint requests to Dr. T. A. M.; Fax: (38 044) 44430 70; E-mail: mirnaya@ionc.kar.net

Z. Naturforsch. 55 a, 895-898 (2000); received July 20, 2000

\begin{abstract}
Phase equilibria of non-mesogenic caesium- and zinc-butyrate mixtures were studied by differential thermal analysis and hot stage polarization microscopy. Smectic liquid crystals were found in some composition range. Their appearance is explained by the latent mesomorphism of caesium butyrate. ${ }^{133} \mathrm{Cs}$ NMR spectra and the specific electrical conductivity of the molten mixtures at $155^{\circ} \mathrm{C}$ were employed to investigate the peculiarities of ionic association and interaction in the melts.
\end{abstract}

Key words: Phase Diagram; Mesophase; Metal Alkanoate.

\section{Introduction}

The phase diagrams of binary metal alkanoates are rather complex because of the strong interaction between the components, which can result in various stable and metastable solid and liquid crystalline phases [1 - 2]. Some pure metal alkanoates have latent (virtual) mesomorphic properties that can show up in binary systems [3]. Caesium butyrate possesses latent mesomorphism and can exhibit it in binaries with alkali-earth metal butyrates [4]. Binary systems of metal alkanoates with asymmetric charged cations, such as univalent alkali and divalent metal cations, may be very interesting and useful since not only ionic mesophases but glasses with optical isotropic and anisotropic properties may be formed [4 - 6].

In the present work the phase diagram of the binary system caesium- and zinc-butyrate has been studied in order to look for the formation of an induced liquid crystalline phase and determine the composition ranges of mesophase and glass. Moreover, an attempt has been made to establish the influence of ionic association and complex formation on the dynamic properties, the NMR spectra of caesium and the ordering processes in the binary metal alkanoate melts.

There exist no data on the phase transition temperatures of this system in literature. As known [6], pure zinc butyrate does not form liquid crystals but supercools and forms glasses easily under cooling this liquid phase. Pure caesium butyrate does not form a mesophase or glass but possesses latent mesomorphic properties [4].

\section{Experimental}

\section{Materials}

Caesium and zinc butyrates were prepared by the methods described in [6, 7]. All salts were free from any water and acid, as evidenced by their IR-spectra. The binary mixtures were prepared by melting the preweighed components under argon and then recrystallizing them at $80{ }^{\circ} \mathrm{C}$ during several hours or days if needed. Samples were stored in argon before the measurements.

\section{Phase Diagram Determination}

The phase diagram was determined by means of both polythermal polarization microscopy and differential thermal analysis. A Paulik-Paulik-Erdey derivatograph $(\mathrm{Q}-1500 \mathrm{D})$ with $\alpha-\mathrm{Al}_{2} \mathrm{O}_{3}$ powder as reference substance was used to obtain thermograms on heating, the heating rates being $2.5{ }^{\circ} \mathrm{C} / \mathrm{min}$. A polarization microscope "Amplival" with hot stage "Boemius" was used to identify mesophases and isotropic liquid phases and thus to determine the 


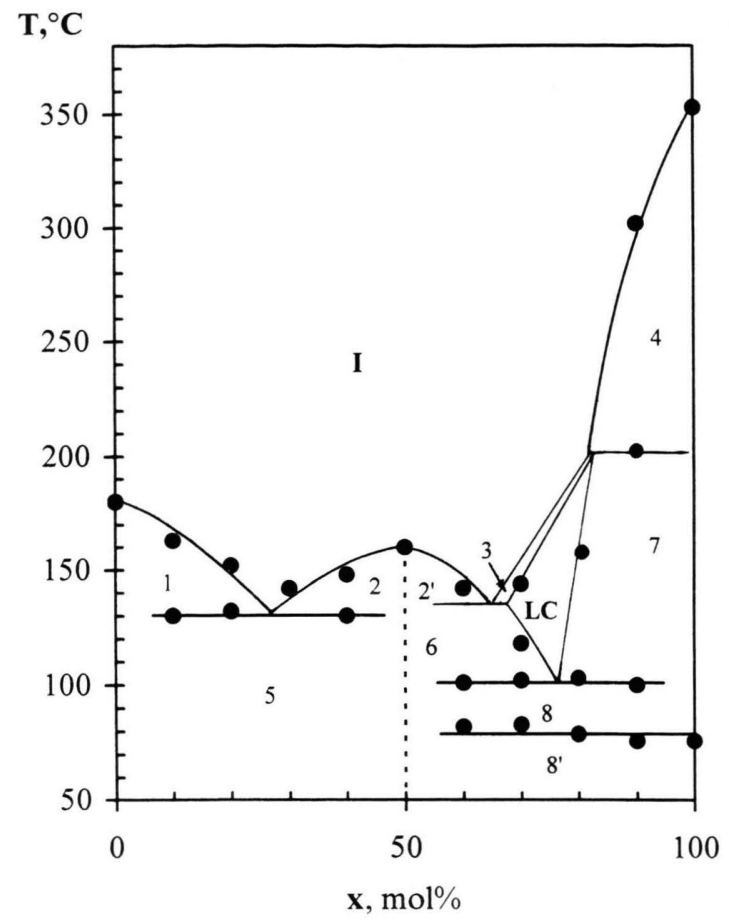

Fig. 1. Phase diagram of $\left\{x \mathrm{C}_{3} \mathrm{H}_{7} \mathrm{COOCs}+(100-\right.$ $\left.x)\left(\mathrm{C}_{3} \mathrm{H}_{7} \mathrm{COO}\right)_{2} \mathrm{Zn}\right\}$. I: isotropic melt, LC: liquid crystalline phase. Arabic numerals stand for heterogeneous two-phase regions as follows: $1:\left(\mathrm{I}+\mathrm{K}_{\mathrm{Zn}}\right), 2$ and $2^{\prime}:\left(\mathrm{I}+\mathrm{K}_{\mathrm{D}}\right), 3$ : $(\mathrm{I}+$ LC), 5: $\left(\mathrm{K}_{\mathrm{Zn}}+\mathrm{K}_{\mathrm{D}}\right), 4:\left(\mathrm{I}+\mathrm{K}_{\mathrm{Cs}}\right), 6:\left(\mathrm{LC}+\mathrm{K}_{\mathrm{D}}\right), 7:(\mathrm{LC}+$ $\left.\mathrm{K}_{\mathrm{Cs}}\right), 8$ and 8': $^{\prime}\left(\mathrm{K}_{\mathrm{Cs}}+\mathrm{K}_{\mathrm{D}}\right)$, where $\mathrm{K}_{\mathrm{Zn}}$ and $\mathrm{K}_{\mathrm{Cs}}$ are the solid phases of pure zinc and caesium butyrates, $\mathrm{K}_{\mathrm{D}}$ is the solid phase of the congruently melting complex.

temperatures of the isotropic melt - mesophase and isotropic - crystal transitions.

The temperatures of phase transitions of the pure salts synthesized in our laboratory were in good agreement with the literature data $[6,7]$. No mesophase was revealed on melting of the pure salts. Caesium butyrate has a solid-solid transition at $76{ }^{\circ} \mathrm{C}$ and melts at $353{ }^{\circ} \mathrm{C}$. Zinc butyrate has no solid-solid transitions and melts into a viscous isotropic liquid at $180{ }^{\circ} \mathrm{C}$ which then supercools and forms a glass.

\section{Conductivity Measurements}

Electrical conductivity isotherm was determined at $155^{\circ} \mathrm{C}$ in the composition range $0-80 \mathrm{~mol} \%$ caesium butyrate (pure zinc butyrate and eight mixtures), i.e. where the melts or supercooling liquids could be obtained. It is experimentally impossible to measure the conductivity isotherm the whole concentration range of the system because the melting points of the components differ much and the melts can not be heated far from their melting point without decomposition. $\mathrm{AC}$ conductivities were measured with an automatic bridge type P-5021 at $1 \mathrm{kHz}$. A capillary quartz cell with Pt electrodes was used. The cell constant was determined by means of a standard melt of $\mathrm{KNO}_{3}$ and was found to be $(21.08 \pm 0.05) \mathrm{cm}^{-1}$. The standard deviation of the conductivity was $\pm 1 \times 10^{-6} \mathrm{~S} \mathrm{~cm}^{-1}$.

\section{${ }^{133}$ Cs NMR Studies}

The ${ }^{133}$ Cs NMR spectra were obtained on a Brucker CXP-200 NMR spectrometer at $155^{\circ} \mathrm{C}$ (working frequency $26.23 \mathrm{MHz}$ ). The compositions of the binary mixtures were in the range $20-80 \mathrm{~mol} \%$ caesium butyrate. A dilute aqueous solution of $\mathrm{CsNO}_{3}$ served as external standard. The spectra of examples studied were each characterized by single resonances corresponding to the central transition $(1 / 2 \Leftrightarrow-1 / 2)$, the linewidth being in the range $(50-200) \mathrm{Hz}$ depending on the composition of the binary molten mixture. The estimated uncertainty of the chemical shifts was $\pm 0.5 \mathrm{ppm}$.

\section{Results and Discussion}

In Fig. 1 shows the phase diagram of the binary system $\left\{x \mathrm{C}_{3} \mathrm{H}_{7} \mathrm{COOCs}+(100-x)\left(\mathrm{C}_{3} \mathrm{H}_{7} \mathrm{COO}\right)_{2} \mathrm{Zn}\right\}$. As seen in figure, three branches of the melting curve intersect at two eutectic points at $130{ }^{\circ} \mathrm{C}, x=25$ $\mathrm{mol} \%$ and at $100^{\circ} \mathrm{C}, x=76 \mathrm{~mol} \%$. A congruently melting complex (D) with equimolar composition has a distectic maximum at $160{ }^{\circ} \mathrm{C}$.

The intermediate homogeneous liquid crystal solution (LC), identified as smectic A, is formed in the system according to the eutectic reaction between the solid phases of caesium butyrate and complex D at $100^{\circ} \mathrm{C}$.

The invariant points, where solid phase coexists with two liquids, isotropic and mesomorphic, are observed at $132{ }^{\circ} \mathrm{C}, x=63 \mathrm{~mol} \%$ and $202{ }^{\circ} \mathrm{C}, x=$ $82 \mathrm{~mol} \%$. They may be named as metatectic and mesoperitectic points, respectively.

It is found that glass formation in the system may be observed in the composition range $0 \mathrm{~mol} \%<x<$ $80 \mathrm{~mol} \%$, vitreous mesophases being obtained in the range $50 \mathrm{~mol} \%<x<80 \mathrm{~mol} \%$.

Figures 2 and 3 present plots of the chemical shift $(\delta)$ and linewidth $(\omega)$ of the ${ }^{133} \mathrm{Cs}$ NMR signal versus 




Fig. $2 .{ }^{133} \mathrm{Cs}$ NMR chemical shifts versus the composition of the system $\left\{x \mathrm{C}_{3} \mathrm{H}_{7} \mathrm{COOCs}+(100-x)\left(\mathrm{C}_{3} \mathrm{H}_{7} \mathrm{COO}\right)_{2} \mathrm{Ca}\right\}$ at $155{ }^{\circ} \mathrm{C}$. I and II are the composition ranges of the system where the equimolar complex D coexist with zinc or caesium butyrate, respectively.

$\omega, \mathbf{H z}$



Fig. $3 .{ }^{133} \mathrm{Cs}$ NMR signal linewidth as a function of the composition of the system $\left\{x \mathrm{C}_{3} \mathrm{H}_{7} \mathrm{COOCs}+(100-\right.$ $\left.x)\left(\mathrm{C}_{3} \mathrm{H}_{7} \mathrm{COO}\right)_{2} \mathrm{Ca}\right\}$ at $155{ }^{\circ} \mathrm{C}$. I and II are the composition ranges of the system where the equimolar complex D coexist with zinc or caesium butyrate, respectively.

the mol fraction of caesium butyrate at $155^{\circ} \mathrm{C}$. The peculiarity of both plots is the existence of special points in the region of the congruently melting complex D formation, at $x=50 \mathrm{~mol} \%$. As seen in Fig. 2, the straight line plot of the chemical shift vs. the composition has here the break. The composition dependence of linewidth (Fig. 3) is characterized by a maximum at $x=50 \mathrm{~mol} \%$.

The general tendency of the $\delta^{133} \mathrm{Cs}$ change with increase of the mol fraction of caesium butyrate is a

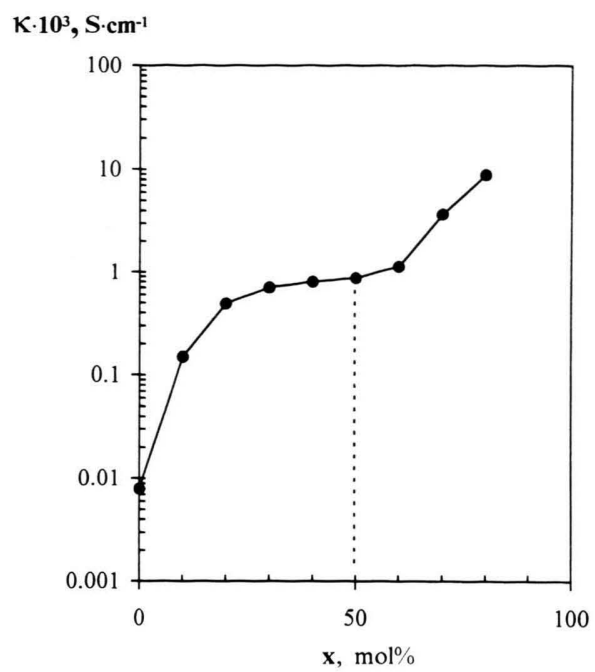

Fig. 4. Dependence of specific electrical conductivity on the composition of the system $\left\{x \mathrm{C}_{3} \mathrm{H}_{7} \mathrm{COOCs}+(100-\right.$ $\left.x)\left(\mathrm{C}_{3} \mathrm{H}_{7} \mathrm{COO}\right)_{2} \mathrm{Ca}\right\}$ at $155^{\circ} \mathrm{C}$.

downfield shift that is indicative of a decrease in the ionic character of the interaction of caesium cations with surrounding anions $[8,9]$. However the velocity of this variation in $\delta^{133} \mathrm{Cs}$ is different in two composition ranges of the system: (I) from pure zinc butyrate up to equimolar complex D, and (II) from this complex up to pure caesium butyrate. As may be seen from Fig. 2, the downfield shift in the first range is characterized by a smaller velocity than in the second range. This difference may be due to the fact that the system may be divided in two sub-systems with the component pairs: complex $\mathrm{D}$ with $\left(\mathrm{C}_{3} \mathrm{H}_{7} \mathrm{COO}\right)_{2} \mathrm{Zn}$ in range I and complex D with $\mathrm{C}_{3} \mathrm{H}_{7}$ COOCs in the range II. So, in the first range caesium cations, fully associated in the complex D, are likely to be in a more symmetrical environment and hence they may be less given to deshielding effect, otherwise they may have more free ion character. In the range II, an increase in concentration of caesium cations, not associated in the complex $\mathrm{D}$, with increase in $x$ is observed. These cations lose their free ion character more and more in interacting with electron donor ligands such as butyrate anions [9].

The linewidth of the ${ }^{133} \mathrm{Cs}$ NMR signal has a maximum magnitude at $x=50 \mathrm{~mol} \%$, i.e. where complex D exists (Figure 3). In diluting the complex D by both zinc and caesium butyrates it is decreased. So, the variation of the linewidth indicates that the caesium cation mobility is minimal 
in the concentration range of the complex $\mathrm{D}$ formation.

The above processes of ionic association and complex formation result in the peculiar isotherm of the electrical conductivity presented in Figure 4. It involves three regions: (1) $0 \mathrm{~mol} \%<x<30 \mathrm{~mol} \%$ where the conductivity increases sharply in adding caesium butyrate to zinc butyrate, (2) $30 \mathrm{~mol} \%<x<$ $70 \mathrm{~mol} \%$ where it exhibits slight alterations, i.e. has a plateau, and (3) $70 \mathrm{~mol} \%<x<100 \mathrm{~mol} \%$ where the conductivity increases notably.

It should be noted that the electrical conductivity of the molten metal alkanoates has an ionic nature [10]. The components of the system studied are distinguished strongly by the extent of ionic dissociation in the melt. So, molten zinc butyrate has a fairly small electric conductivity (by four orders less than molten caesium butyrate does) that is indicative of its very little ionic dissociation. Compared to the ionic melt caesium butyrate, molten zinc butyrate may be considered as a quasi-molecular liquid.

[1] Molten Alkali Metal Alkanoates, IUPAC Solubility Data Series, Vol. 33 (P. Franzosini, ed.), Pergamon Press, Oxford 1988.

[2] T. A. Mirnaya, V. D. Prisyazhnyi, and V. A. Shcherbakov, Russian Chem. Rev. 58, 821 (1989).

[3] T. A. Mirnaya, Ukrainian Chem. J. 63, 3 (1998).

[4] T. A. Mirnaya, V. S. Dradrakh, and G. G. Yaremchuk, Z. Naturforsch. 54a, 685 (1999).

[5] T. A. Mirnaya, Y. V. Bereznitski, and S. V. Volkov, Z. Naturforsch. 51a, 867 (1996).

[6] T. A. Mirnaya, G. G. Yaremchuk, V. S. Dradrakh, and S. V. Volkov, Russian J. Inorg. Chem. 44, 775 (1999).
Therefore it is clear that an addition of caesium butyrate to zinc butyrate results in a growth of the number of charge carriers in the system owing to the increase in the amount of caesium cations, the mobility of which varies nonmonotonously as evidenced by concentration dependence of the linewidth of the ${ }^{133}$ Cs NMR signal (Figure 3). However these factors together give rise to a general enlargement of electrical conductivity with increase in caesium butyrate percentage, but with different velocities in three concentration ranges of the system (Figure 4).

Thus, the binary system of zinc and caesium butyrates is characterized by pronounced interionic interactions, such as ionic complex formation and association. They are shown to be the reason of the formation of an intermediate liquid crystalline phase and glasses in some concentration ranges of the system. The conductivity data and parameters of ${ }^{133} \mathrm{Cs}$ NMR spectra of the binary melts studied are interrelated and agree well with the phase diagram of the system.

[7] M. Sanesi, P. Ferloni, M. Zangen, and P. Franzosini, Z. Naturforsch. 32a, 285 (1977).

[8] J. Kondo and J. Yamashita, J. Phys. Chem. Solids 10, 245 (1959).

[9] T. A. Mirnaya, G. G. Yaremchuk, and V. V. Trachevski, Russian J. Inorg. Chem. 36, 1269 (1991).

[10] M. Sanesi, A. Cingolani, P. L. Tonelli, and P. Franzosini, Thermodynamic and Transport Properties of Organic Salts, IUPAC Chemical Data Series No 28, (P. Franzosini and M. Sanesi, eds.), Pergamon Press, Oxford 1980. 